\title{
Chemical Bonding between Phenolic Resins and Polyhedral Oligomeric Silsesquioxanes (POSS) in Inorganic-Organic Hybrid Nanocomposites
}

\author{
Charles U. Pittman Jr., ${ }^{1,2}$ Gui Zhi Li, ${ }^{1}$ and Ho Souk Cho ${ }^{1}$
}

ERRATUM TO: JOURNAL OF INORGANIC AND ORGANOMETALLIC POLYMERS AND MATERIALS DOI: 10.1007/s10904-006-9028-9

The submitted and accepted dates for this paper were inadvertently omitted. The dates are as follows:

Submitted September 16, 2005; accepted October 3, 2005

The online version of the original article can be found at http:// dx.doi.org/10.1007/s10904-006-9028-9

${ }^{1}$ Department of Chemistry, Mississippi State University, Box 9573Mississippi State, MS, 39762, USA.

2 To whom correspondence should be addressed.

E-mail: cpittman@ra.msstate.edu 